\title{
SMOKE-FREE POLICIES AND NON-SMOKERS' REACTIONS TO SHS EXPOSURE IN SMALL AND MEDIUM ENTERPRISES
}

\section{CALLIOPI SIVRI ${ }^{1}$, LAMBROS LAZURAS $^{2}$, ANGELOS RODAFINOS ${ }^{1}$, and JOHN RICHARD EISER ${ }^{3}$}

\author{
${ }^{1}$ International Faculty of the University of Sheffield, Thessaloniki, Greece \\ Department of Psychology \\ ${ }^{2}$ South-East European Research Centre (SEERC), Thessaloniki, Greece \\ ${ }^{3}$ University of Sheffield, Sheffield, United Kingdom \\ Department of Psychology
}

\begin{abstract}
Introduction: Non-smoker employees can significantly improve the existing smoke-free policies in the workplace by asserting their right for smoke-free air and confronting smoker colleagues. The aim of the study was to assess the psychological and social drivers of non-smokers' readiness to assert their right for smoke-free air in the workplace. Materials and Methods: Twenty-six small-and-medium enterprises (SME) with diverse background were randomly selected, and 284 employees agreed to participate in the study. Our study focused on the responses of 85 non-smokers (M age $=34$ years, $\mathrm{SD}=7.98,84.2 \%$ worked in indoor offices). A cross-sectional design was used and participants completed a structured anonymous questionnaire assessing background and demographic characteristics, and psychosocial predictors of assertiveness intentions. Results: Although more than half of non-smokers reported they were often/almost always bothered by exposure to SHS, roughly one third of them reported having asked their colleagues not to smoke at work. Regression analysis showed that the effects of distal predictors (i.e. annoyance due to SHS exposure) were mediated by past behaviour, attitudes (protection motivation beliefs), social norms, and self-efficacy. Conclusions: Health beliefs related to SHS exposure, and concerns about workplace health and job performance, social norms and self-efficacy can increase the assertiveness of non-smokers in workplace settings. Related campaigns should focus on communicating normative messages and self-efficacy training to empower non-smoker employees to act assertively towards protecting their smoke-free rights.

Keywords:
\end{abstract}

Non-smokers' assertiveness, Smoke-free workplace, Attitudes, SHS exposure

\section{INTRODUCTION}

Exposure to second-hand-smoke (SHS) causes fatal diseases including heart disease, and lung cancer [1,2]. The Framework Convention on Tobacco Control (FCTC) requires signatory countries to take measures against SHS exposure in public settings and workplaces. Evidence has shown that smoke-free policies at work reduce the overall burden of exposure to SHS, eliminate smoking cues, encourage smoking cessation among smoker employees [3-5], and result in higher financial returns and overall profit for the company and the public health system [6]. The implementation of smoke-free policies, however, is not always welcomed by smokers, who may resist change and violate smoking restrictions [7]. Even in this

Received: July 10, 2012. Accepted: October 11, 2013.

This study was financially supported by a Cancer Research UK grant: C3841/A8924.

Corresponding author: L. Lazuras, South-East European Research Centre, 24 Prox. Koromila Street, 546 22, Thessaloniki, Greece (e-mail: llazuras@seerc.org). 
case, non-smokers may still be able to protect their health from SHS exposure by asserting their right for smoke-free air $[8,9]$.

Non-smokers are more willing to assert their right for smoke-free air in the workplace than in other public settings [10]. The first studies in this area showed that almost half of non-smoking employees reported being assertive and asking their smoker colleagues not to smoke in smokefree areas [9-11]. Yet, very little research has been devoted to identifying the psycho-social drivers of non-smokers' assertiveness. Among the few reported studies, Willemsen and DeVries [10] showed that assertiveness intentions were predicted by the key variables of the Attitude-Social norms-Efficacy (ASE) model, namely positive attitudes towards assertiveness, having other colleagues who acted assertively against SHS exposure (normative influence), self-efficacy, and annoyance due to SHS exposure. A more recent study showed that attitudes to assertiveness did not predict assertiveness intentions, and highlighted the importance of past behavior in predicting intentions to act assertively in the future [12].

The aforementioned studies provided mixed findings regarding the role of attitudes, and this can be attributed to inconsistencies in attitude measurement. Specifically, in these studies, attitudes towards assertiveness were assessed either with single item measures [10], or with pairs of evaluative adjectives, such as good/bad and unethical/ ethical [12]. This method of attitude assessment offers little insight into the reasons and specific beliefs that drive non-smokers' assertiveness.

SMEs represent a main driver of economy in Europe [13]. Efforts to reduce smoking- related costs (e.g. absenteeism, sick-leave, health care and insurance costs) and promote smoke-free workplaces will greatly contribute to the economic sustainability of SMEs $[14,15]$. Thus, better understanding non-smokers' readiness to act assertively against SHS exposure is important because assertiveness can facilitate the successful implementation of smoke-free policies [10]. This is even more important in countries such as Greece, where tobacco control policies are poorly implemented, and many smokers report violation of existing smoke-free regulations [7,16].

The objective of the present study was to assess nonsmokers' assertiveness in SMEs and identify the psychosocial drivers of assertive behavior. In order to fill in the gaps identified in previous studies, we used a multi-item measure of attitudes towards assertiveness assessing behavioral beliefs pertaining to health protection motivation and productivity, and social aspects (common courtesy approach) of assertiveness.

These dimensions were identified in previous studies of non-smokers' assertiveness [8], and are consistent with theoretical approaches that explain health protection motivation [17]. We also included measurements of health beliefs related to SHS exposure in order to further explore the relationship of this variable with perceived annoyance resulting from SHS exposure and intentions to act assertively.

\section{METHODS}

\section{Participants and procedure}

A multistage cluster sampling approach was used. This sampling approach allows for an easy and fairly rapid data collection, once the target population is identified. It allows for more careful and inexpensive sampling of the target population when the population's features have been identified. During the first stage, 26 SMEs based in Thessaloniki (second largest city in Greece with approx. $1 \mathrm{~m}$ inhabitants) were selected, and all of them agreed to participate. Slightly more than half $(58 \%)$ of the selected SMEs employed $\leq 50$ employees, and $42 \%$ employed between 51 and 100 employees. The participating SMEs came from diverse backgrounds, including education services $(22.2 \%)$, banking, finance and insurance $(20.8 \%)$, telecommunications (12\%), trading and logistics (11.6\%), marketing and advertising (8.5\%), food and drinking 
(7.7\%), construction and engineering industry (2.8\%), and healthcare services (1.8\%).

During the second stage of the sampling process, all employees working in the selected SMEs were eligible to participate. Overall, 320 employees were approached and 284 agreed to participate in the study, thus yielding a high response rate $(88.7 \%)$. Among these participants, $127(44.7 \%)$ were males, 140 (49.3\%) were females, and $17(6 \%)$ individuals did not declare their gender. Thirty-six employees (12.6\% of the total sample) did not declare their SMEs background. The mean age of the respondents was 34 years $(\mathrm{SD}=7.98)$ and the vast majority of them $(84.2 \%)$ worked in indoor areas.

In line with the Ethics Guidelines of the British Psychological Society, all participants were informed about the purposes of the study, were free to ask questions or withdraw from the study without any prior notice or adverse consequences, and completed questionnaires on-site. Survey completion lasted approximately $10 \mathrm{~min}$. Ethics approval for the study was granted by the respective Ethics Committee of the International Faculty of the University of Sheffield.

\section{Measures}

A structured questionnaire that was adopted from previous studies on assertive behavior $[8,10,12]$ was used. The measures included demographic (age and gender) and jobrelated variables (i.e. job status, type of working area, type of smoke-free policy used), self-reported smoking status, health beliefs towards SHS exposure, annoyance due to SHS exposure at work, past assertive behavior, social cognitions (attitudes, social norms, self-efficacy), and behavioral intentions related to non-smokers' assertiveness at work. Internal consistency reliability (Cronbach's $\alpha$ ) was at acceptable levels in all multi-item continuous measures used and it is reported where relevant as follows.

Age was assessed with an open-ended question "how old are you?", and gender was assessed on a nominal scale (1-male, 2 -female).
Job status was measured with the item "Please describe your job position" followed by five response options (executive officer or manager, secretary/clerk, sales, technical support, other). In subsequent analysis, these categories were collapsed to create a new variable describing higher status position (only executive officers and managers), and lower status jobs (secretarial, sales, and technical support). The type of working area was described with the following response options: private office, shared office, open plan office (indoors), shopping floor (indoors), outdoor facility or other. These categories were collapsed to create a nominal variable distinguishing between indoor and outdoor working areas.

The type of smoking policy in place was assessed with the question "Which of the following describes best the smoking policy used in your company?" followed by three response options, 1 - smoking is prohibited in all indoor working areas (total restriction of indoor smoking), 2 smoking is allowed only in certain indoor areas/smoking zones (partial restriction of indoor smoking), and 3 smoking is allowed everywhere indoors (no smoke-free policy in place).

The self-reported smoking status was assessed with the question "Do you smoke?", followed by four response options, 1 - I don't smoke, 2 - I used to smoke but I have given it up, 3 - I smoke but only occasionally, and 4 - I smoke at least one cigarette a day.

Annoyance resulting from SHS exposure at work was assessed with the mean of two items (i.e. "are you bothered if a smoker colleague smokes in your working area?' and 'have you ever moved away, or wanted to move away from your working area because of exposure to SHS?"), and responses were coded on a 5-point continuous scale, 1 never, 5 - almost always (Cronbach's $\alpha=0.70$ ).

SHS exposure health beliefs were assessed with the stem proposition "Let's assume that every day in your working area you are exposed to the smoke coming from the cigarettes of your smoker colleagues. How likely do you think 
it is that in the future you will suffer from...serious breathing/respiratory problems, lung cancer, heart disease?" The responses were coded on a typical 5-point Likert scale, 1 - extremely unlikely, 5 - extremely likely, and the mean score was computed with higher scores reflecting greater perceived likelihood of suffering from SHS exposure-related disease in the future (Cronbach's $\alpha=0.88$ ).

Past assertive behavior was assessed with a single item "Have you ever asked a smoker colleague not to smoke in your working area?", and responses were coded on a 5-point continuous scale, 1 - never, 5 - almost always.

Attitudes towards assertiveness were assessed with the stem proposition "To ask my smoker colleagues not to smoke in my working area is..." followed by eight items scored on a typical 5-point Likert scale, 1 - strongly disagree, 5 strongly agree. Principal components factor analysis (reported in the results section) showed that the measure assessed two facets of attitudes towards assertiveness, namely "common courtesy" and "health protection motivation and productivity." The internal consistency reliability of the measure was high overall (Cronbach's $\alpha=0.78$ ), and for the subscales of "common courtesy" (Cronbach's $\alpha=0.85$ ), and "health protection motivation and productivity" (Cronbach's $\alpha=0.84$ ) it was high as well.

Social norm was measured with a single item reflecting the perceived prevalence of assertiveness among other nonsmokers at work ("How often do other non-smoker colleagues ask smokers not to smoke in their working area?") and it was scored on a 5-point continuous scale, 1 - never, 5 - almost always.

Self-efficacy was measured with the step proposition "Asking smoker colleagues not to smoke in my working area is..." followed by two items (very hard/very easy; impossible/possible) scored on 7-point continuous scales. A mean score was computed and higher scores reflected greater self-efficacy to act assertively (Cronbach's $\alpha=0.69$ ).

Assertiveness intention was assessed with a single item "Do you intend to ask smoker colleagues not to smoke in your working area?", and scores were coded on a 5-point Likert scale, 1 - definitely not, 5 - definitely yes. Higher scores reflected a greater intention to act assertively.

\section{Statistical analysis}

Statistical software IBM SPSS 19.0 was used for data analysis. The analysis of frequencies was used to report percentages reflecting the existence of smoke-free policies, perceived health risk and annoyance due to SHS exposure, and past assertive behavior. One way Analysis of Variance (ANOVA) was used to indicate differences in self-reported assertiveness, assertiveness intentions, and perceived assertiveness of colleagues by job status and type of smokefree policy. Exploratory factor analysis with principal component analysis (PCA) were applied to assess the factorial structure of the attitudes towards assertiveness measure. Varimax rotation was used, eigenvalues $>1$ were selected, and factor loadings $>0.70$ were used. Multiple linear regression analysis was applied to identify the predictors of non-smoker employees' assertiveness. The stepwise method was used to assess the unique effects of distal and proximal predictors of assertive intentions in each step. Finally, univariate regression analysis was employed to assess the effects of SHS-related health beliefs on perceived annoyance resulting from SHS exposure. In all the analyses, the statistical significance level was established as $p>0.05$, and the confidence intervals were set at $95 \%$.

\section{RESULTS}

The means, standard deviations, and internal consistency scores of the continuous measures used in the study are presented in Table 1.

\section{Smoke-free policy at work and self-reported smoking status}

The majority $(78.6 \%, \mathrm{~N}=187)$ of the respondents reported a total ban on indoor smoking, $16.8 \%(\mathrm{~N}=40)$ reported a partial ban, and only $4.6 \%(\mathrm{~N}=11)$ reported that 
Table 1. Intercorrelations among the study variables

\begin{tabular}{lcccccccc}
\hline \multicolumn{1}{c}{ Variables } & \multicolumn{10}{c}{ Correlations } \\
\cline { 2 - 9 } & 1 & 2 & 3 & 4 & 5 & 6 & 7 & 8 \\
\hline 1. Intentions & - & $0.33^{*}$ & 0.12 & $0.54^{*}$ & 0.05 & $0.49^{*}$ & $0.35^{*}$ & $0.40^{*}$ \\
2. Annoyance due to SHS exposure & & - & $0.31^{*}$ & $0.64^{*}$ & 0.16 & $0.50^{*}$ & 0.21 & 0.14 \\
3. SHS-related health beliefs & & & - & 0.17 & 0.01 & $0.47^{*}$ & $0.29^{*}$ & 0.11 \\
4. Past assertive behavior & & & & - & 0.02 & $0.36^{*}$ & $0.31^{*}$ & $0.39^{*}$ \\
5. Attitudes (common courtesy) & & & & & - & 0.09 & 0.05 & $-0.22^{*}$ \\
6. Attitudes (protection motivation) & & & & & & - & 0.18 & $0.23^{*}$ \\
7. Social norms & & & & & & & - & $0.29^{*}$ \\
8. Self-efficacy & & & & & & & & - \\
M & 3.76 & 3.39 & 4.01 & 2.98 & 2.75 & 4.19 & 2.77 & 4.90 \\
SD & 1.03 & 1.06 & 0.86 & 1.25 & 0.95 & 0.72 & 0.94 & 1.31 \\
\hline
\end{tabular}

*p $<0.05$.

there was no smoke-free policy at all. Regarding the smoking status, $38.9 \%(\mathrm{~N}=110)$ reported smoking at least one cigarette a day, $23.7 \%(\mathrm{~N}=67)$ said they smoked on an occasional basis, $13.1 \%(\mathrm{~N}=37)$ were ex-smokers (used to smoke but they have it given up), and only $24.4 \%(\mathrm{~N}=69)$ reported they have never smoked. Given the scope of the present study, only indoor non-smoker employees $(\mathrm{N}=85)$ were included in the subsequent analysis.

\section{SHS exposure beliefs, annoyance,}

\section{and self-reported assertiveness}

Regarding SHS exposure-related health beliefs, the majority of non-smoker indoor employees reported that chronic SHS exposure at work was likely/very likely to lead to serious breathing problems (66.6\%), lung cancer $(73.8 \%)$, and heart disease (71.4\%). Also, more than half (54.2\%) reported they were often/almost always bothered by exposure to SHS, $26.5 \%$ said they were bothered sometimes, and only 19.3 reported they were either rarely or never bothered by SHS. Nevertheless, only $32.6 \%$ reported having asked (often/always) their colleagues not to smoke at work, $27.7 \%$ had done it sometimes, and 39.8\% had never or rarely asked smoker colleagues not to smoke.
One-way ANOVA showed that executives (higher status employees) reported stronger intentions $(\mathrm{M}=4.12$, 95\% CI: 3.74-4.50) to be assertive in the future, than lower-status employees ( $\mathrm{M}=3.56,95 \%$ CI: 3.29-3.83) $\left(\mathrm{F}(1,83)=5.27, \mathrm{p}<0.05, \eta^{2}=0.06\right)$. Further analysis did not indicate a significant difference $(\mathrm{p}>0.05)$ in assertiveness intention, past assertive behavior, and perceived assertiveness of other colleagues as regards the reported smoking policy at work (partial, total, no ban).

\section{Attitudes towards assertiveness}

Principal component analysis (PCA) was used to assess the structure of the assertiveness attitudes measure. The data were inspected and found suitable for analysis of principal components $(\mathrm{KMO}=0.73$, Bartlett's tests $=334.49$, $\mathrm{p}<0.0001)$. The analysis revealed the existence of two factors totally explaining $71.5 \%$ of the variance. Four items related to common courtesy (i.e. 'being the bad guy', 'problems in relationships with colleagues', 'discomfort', and 'trouble') loaded on a single factor explaining 36.5\% of the variance, with factor loadings ranging between 0.774 and 0.889. Accordingly, four items related to health protection motivation and productivity (i.e. 'cleaner workplace', 
'improve working conditions', 'make me feel more productive', and 'protect my health from SHS exposure') loaded on the second factor (factor loadings between 0.725 and 0.893 ), and explained $35.05 \%$ of the variance. Each factor had acceptable levels of internal consistency reliability (Cronbach's $\alpha>0.80$ ).

\section{Predicting assertiveness intentions}

A stepwise linear regression analysis was used to assess the predictors of non-smokers' assertiveness intentions. Predictors included past behaviour, annoyance from exposure to SHS at work, SHS exposure-related health beliefs, attitudes towards assertiveness reflecting 'common courtesy' and 'health protection motivation and productivity' dimensions, social norms (i.e. prevalence of other non-smoker colleagues acting assertively), and self-efficacy. Past behavior, attitudes, social norms, and self-efficacy towards a given behavior are proxy predictors of behavioral intentions, and are assumed to mediate the effects of more distal predictors [19]. Therefore, the distal predictors (i.e. annoyance resulting from SHS exposure, and
SHS exposure-related health beliefs) in the present study were entered in the first step of the analysis, and the proxy predictors (i.e. past behavior, attitudes, norms, and selfefficacy towards assertiveness) were entered in the second step. An overall significant model emerged predicting $52.1 \%\left(\operatorname{Adj} R^{2}\right)$ of the variance in assertiveness intentions. During the first step of the analysis (Adj $R^{2}=11.2 \%$ ), only annoyance resulting from SHS exposure significantly predicted intentions $(\beta=0.369, p<0.005)$. During the second step, the predicted variance in intentions significantly increased to $52.1 \%$ and significant predictors included past assertive behavior $(\beta=0.451, \mathrm{p}<0.001)$, social norms $(\beta=0.233, p<0.05)$, self-efficacy $(\beta=0.220, p<0.05)$, and attitudes related to health protection motivation and productivity $(\beta=0.268, \mathrm{p}<0.05)$. The results from the regression analysis are summarized in Table 2.

\section{The role of health beliefs}

A univariate linear regression analysis was also used to assess the effects of SHS-related health beliefs on perceived annoyance due to SHS exposure. The analysis showed

Table 2. Psychosocial predictors of intentions to act assertively

\begin{tabular}{lcccc}
\hline \multicolumn{1}{c}{ Predictors } & B & $\beta$ & $95 \%$ CI for B & Adj $R^{2}$ \\
\hline Step 1 & & & & \\
$\quad$ annoyance due to SHS exposure & 0.352 & $0.369^{* *}$ & $0.133-0.572$ & 0.112 \\
SHS-related health beliefs & -0.003 & -0.003 & $-0.265-0.259$ & \\
Step 2 & & & & \\
annoyance due to SHS exposure & -0.083 & -0.087 & $-0.311-0.145$ & 0.521 \\
SHS-related health beliefs & -0.159 & -0.139 & $-0.374-0.057$ & \\
past assertive behavior & 0.368 & $0.451^{* * *}$ & $0.186-0.550$ & \\
attitudes (common courtesy) & 0.025 & 0.023 & $-0.160-0.209$ & \\
attitudes (protection motivation) & 0.401 & $0.268^{*}$ & $0.081-0.720$ & \\
social norms & 0.242 & $0.233^{*}$ & $0.055-0.429$ & \\
self-efficacy & 0.168 & $0.220^{*}$ & $0.025-0.312$ & \\
\hline
\end{tabular}

B - unstandardized regression coefficients.

$\beta$-standardized regression coefficients.

CI $-95 \%$ confidence interval.

Adj $R^{2}$-Adjusted $\mathrm{R}^{2}$. 
that health beliefs significantly predicted annoyance resulting from SHS exposure $(F(1,81)=8.99, \mathrm{p}<0.005$, Adj $\left.R^{2}=8.9 \%, \beta=0.319,95 \% \mathrm{CI}=0.130-0.642\right)$.

\section{DISCUSSION}

The present study assessed assertiveness intentions among non-smoker employees in SMEs. Firstly, although the majority of non-smokers acknowledged the detrimental health effects of SHS exposure, and more than half reported being annoyed due to SHS exposure at work, roughly one third had asked smoker colleagues not to smoke in the past. This finding is in line with previous studies [12], and shows that more effort is needed to motivate non-smokers adopt a confrontational approach when their right to smoke-free air and, consequently, their health is threatened. This seems to be a greater concern for employees with lower job status, who appeared to be more reluctant to act assertively as compared to higher-status employees (e.g. company executives). This implies inequality in the way employees perceive and act upon their rights for a healthier workplace, and should be further addressed in studies of assertiveness and workplace smoking.

Secondly, the results from the first regression analysis reflected a hierarchical model of assertiveness (see Figure 1), whereby the effects of distal predictors (i.e. annoyance resulting from SHS exposure) are mediated by past behavior and social cognitions specific to assertiveness, namely attitudes, social norms, and self-efficacy. This lends support to previous studies showing that the social cognitive variables described in the Attitude-Social norms-Efficacy model can be effectively used to predict non-smokers' assertiveness at work [10,12]. Also, in line with Willemsen and DeVries [10], further analysis showed that SHS-related health beliefs directly predicted annoyance from SHS exposure, but not assertive intentions. These findings suggest that nonsmokers perceiving exposure to SHS as dangerous to their health are more likely to be annoyed by it, and, in turn,

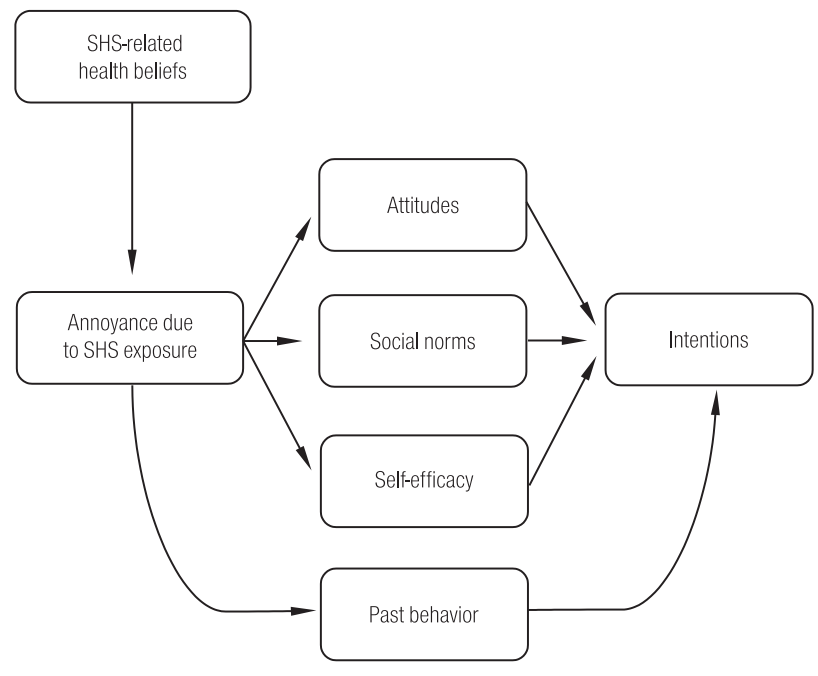

Fig. 1. Hierarchical model of non-smokers' assertiveness

more willing to follow the confrontational (and not the common courtesy) route to assertiveness.

Thirdly, and perhaps most importantly, the present study provided a novel way to assess attitudes towards nonsmokers' assertiveness, and perhaps overcome the inconsistencies noted in previous studies. In particular, the principal component analysis supported a two-dimensional model of assertiveness attitudes, respectively reflecting behavioral beliefs towards social courtesy (i.e. the negative impact of assertiveness on relationships with smoker colleagues) and motivation to protect health and improve job performance.

Both dimensions had high internal consistency reliability scores, and correlated significantly and in the expected directions with other assertiveness-related psychosocial variables. Although further research is necessary, these results provide some support for the measure's reliability and validity. Furthermore, the regression analysis indicated that the attitude component reflecting health protection and productivity motivation, significantly predicted intentions to act assertively, over and above the effects of other predictors. This finding highlights the importance of attitudes in non-smokers' assertiveness research, and the need to consider attitude measures that 
reflect assertiveness-specific concerns and behavioral tendencies.

On the practical side, the present study has implications for efforts to promote non-smokers' assertiveness in the workplace. It appears that tobacco control campaigns or worksite health education programs would benefit by tapping SHS-related health beliefs, and making concerns about workplace health and job performance salient. The normative influences (i.e. conveying the prototype of assertiveness as the norm among non-smokers), and self-efficacy training can further empower non-smoker employees to act assertively. Most importantly, such campaigns should acknowledge potential job-status-related inequalities in assertiveness, and accordingly make their messages appealing to both higher and lower status employees.

The present study was not free of limitations. Firstly, a larger sample of companies and non-smoker employees could be used to allow for a sophisticated analysis, such as hierarchical linear (multilevel) and multiple mediation modelling. Secondly, air quality measures could be used to assess SHS-related pollution in the selected workplaces and accordingly draw comparisons in perceived annoyance, and assertive intentions and behavior.

To conclude, our findings suggest that social cognition models of behavior are relevant to the study of non-smokers' assertiveness in workplace settings. Specific beliefs, such as attitudes towards protection of one's own health, self-efficacy, and social norms can validly predict nonsmoker's motivation to act assertively towards protecting their rights for smoke-free air. More research is needed to address the role of job status inequalities in assertive behavior, and to identify other relevant predictors of behavior.

\section{ACKNOWLEDGEMENTS}

We are grateful to the SMEs and employees that participated in our study.

\section{REFERENCES}

1. Asomaning K, Miller DP, Liu G, Wain JC, Lynch TJ, Su L, et al. Secondhand smoke, age of exposure and lung cancer risk. Lung Cancer. 2008;61:13-20, http://dx.doi.org/10.1016/ j.lungcan.2007.11.013.

2. Barnoya J, Glantz SA. Cardiovascular effects of secondhand smoke: Nearly as large as smoking. Circulation. 2005;111:2684-98, http://dx.doi.org/10.1161/CIRCULATIONAHA.104.492215.

3. Fichtenberg CM, Glantz SA. Effect of smoke-free workplaces on smoking behaviour: Systematic review. BMJ. 2002;325:188-95, http://dx.doi.org/10.1136/bmj.325.7357.188.

4. Gao JN, Zheng PP, Gao JL, Chapman S, Fu H. Workplace smoking policies and their association with employees' smoking behaviours. A cross-sectional survey in China. Tobacco Control. 2011;20:131-36, http://dx.doi.org/10.1136/tc.2010.036335.

5. Halpern MT, Taylor H. Employee and employer support for workplace-based smoking cessation: results from an international survey. J Occup Health. 2010;52:375-82, http://dx.doi. org/10.1539/joh.L10075.

6. Rasmussen SR, Prescott E, Sorensen TIA, Sogaard J. The total lifetime health cost savings of smoking cessation to society. Eur J Public Health. 2005;15:601-6, http://dx.doi. org/10.1093/eurpub/cki024.

7. Lazuras L, Eiser JR, Rodafinos A. Predicting smokers' non-compliance with smoking restrictions in public places. Tobacco Control. 2009;18:127-31, http://dx.doi.org/10.1136/ tc. 2008.025841.

8. Germain D, Wakefield M, Durkin S. Non-smokers' responses when smokers light up: A population-based study. Prev Med. 2007;45:21-5, http://dx.doi.org/10.1016/j.ypmed.2007.03.012.

9. Gottlieb NH, Nelson A. A systematic effort to reduce smoking at the workplace. Health Educ Quart. 1990;17:99-118, http://dx.doi.org/10.1177/109019819001700110.

10. Willemsen MC, De Vries H Saying "No" to environmental tobacco smoke: determinants of assertiveness among non-smoking employees. Prev Med. 1996;25:575-82, http:// dx.doi.org/10.1006/pmed.1996.0092. 
11. Willemsen MC, De Vries H, Genders R. Annoyance from environmental tobacco smoke and support for no-smoking policies at eight large Dutch workplaces. Tobacco Control. 1996;5:132-8, http://dx.doi.org/10.1136/tc.5.2.132.

12. Aspropoulos E, Lazuras L, Rodafinos A, Eiser JR. Can you please put it out? Predicting non-smokers' assertiveness intentions at work. Tobacco Control. 2010;19:148-52, http:// dx.doi.org/10.1136/tc.2009.031161.

13. Hasle P, Limborg HJ. A review of the literature on preventive occupational health and safety activities in small enterprises. Industrial Health. 2006;44:6-12, http://dx.doi. org/10.2486/indhealth.44.6.

14. Bunn WB, Stave GM, Downs KE, Alvir JM, Dirani R. Effects of smoking status on productivity loss. JOEM. 2006;48:1099-1108.

15. Tsai SP, Wen CP, Hu SC, Cheng TY, Huang SJ. Workplace smoking related absenteeism and productivity costs in Taiwan. Tobacco Control. 2005;14:i33-7, http://dx.doi. org/10.1136/tc.2003.005561.

16. Vardavas CI, Kafatos A. Smoking policy and prevalence in Greece: An overview. Eur J Public Health. 2007;17:211-3, http://dx.doi.org/10.1093/eurpub/ckl094.

17. Prentice-Dunn S, Rogers RW. Protection Motivation Theory and preventive health:Beyond the Health Belief Model. Health Educ Res. 1986;1:153-61, http://dx.doi.org/10.1093/ her/1.3.153.

18. Bogdanovica I, Godfrey F, McNeil A, Britton J. Smoking prevalence in the European Union:A comparison of national and transnational prevalence survey methods and results. Tobacco Control. 2011;20:e4, http://dx.doi.org/10.1136/ tc.2010.036103.

19. Fishbein M, Yzer MC. Using theory to design effective health behaviour interventions. Commun Theory. 2003;13:164-83, http://dx.doi.org/10.1111/j.1468-2885.2003.tb00287.x.

This work is available in Open Access model and licensed under a Creative Commons Attribution-NonCommercial 3.0 Poland License - http://creativecommons.org/ licenses/by-nc/3.0/pl/deed.en. 